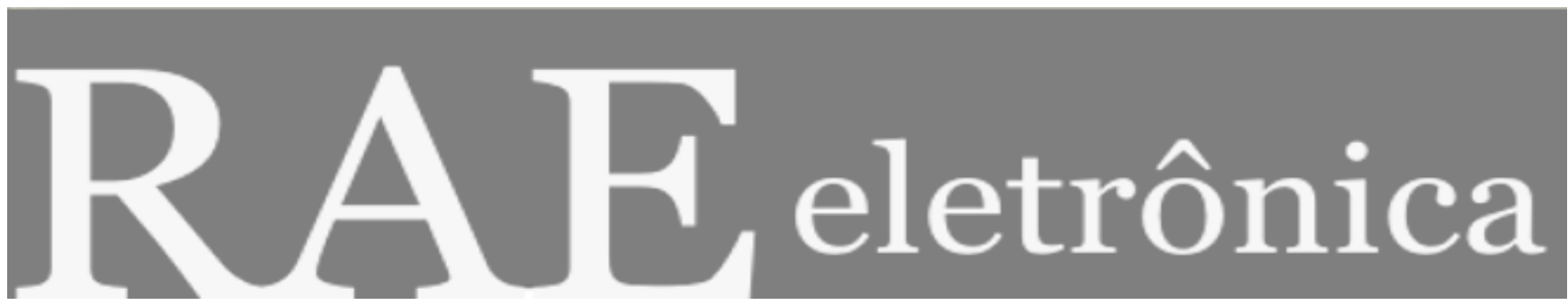

\title{
A GESTÃO DO CONHECIMENTO: \\ CONECTANDO ESTRATÉGIA E VALOR PARA A EMPRESA
}

Por:

William Sampaio Francini

RAE-eletrônica, Volume 1, Número 2, jul-dez/2002.

http://www.rae.com.br/eletronica/index.cfm?FuseAction=Artigo\&ID=1459\&Secao=PWC\&Volume=1 $\&$ Numero $=2 \& A n o=2002$

CCopyright, 2002, RAE-eletrônica. Todos os direitos, inclusive de tradução, são reservados. É permitido citar parte de artigos sem autorização prévia desde que seja identificada a fonte. A reprodução total de artigos é proibida. Os artigos só devem ser usados para uso pessoal e nãocomercial. Em caso de dúvidas, consulte a redação: redacao@rae.com.br.

A RAE-eletrônica é a revista on-line da FGV-EAESP, totalmente aberta e criada com o objetivo de agilizar a veiculação de trabalhos inéditos. Lançada em janeiro de 2002, com perfil acadêmico, é dedicada a professores, pesquisadores e estudantes. Para mais informações consulte o site www.rae.com.br/eletronica.

RAE-eletrônica

ISSN 1676-5648

(C2002 Editora: Fundação Getulio Vargas - Escola de Administração

de Empresas de São Paulo.

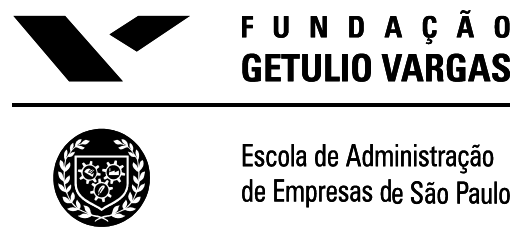




\title{
A GESTÃO DO CONHECIMENTO: CONECTANDO ESTRATÉGIA E VALOR PARA A EMPRESA
}

\section{William Sampaio Francini}

Bacharel em Economia pela PUC-SP, Mestrando em Administração pela FGV-EAESP, Assistente de Pesquisa no NPP.

E-mail:francini@fgvsp.br

\section{RESUMO}

Novas Tecnologias de Comunicação e Informação trazem possibilidades e questões ainda não exploradas a respeito da gestão do conhecimento nas organizações, tanto convencionais como virtuais. As tendências na direção de automação e virtualização devem ser consideradas sob seus aspectos estratégicos, tais como a obtenção de vantagem competitiva através do uso combinado destas tecnologias, a gestão de conhecimento e o aprendizado organizacional. Aspectos específicos relacionados às estratégias de geração, retenção e disseminação do conhecimento, das próprias organizações e respectivos colaboradores, assim como sua dinâmica e possíveis impactos sobre os resultados das empresas, consistem na preocupação central deste trabalho.

\begin{abstract}
New Information and Communication Technologies bring along with them new possibilities and questions that have not yet been explored considering knowledge management in organizations, neither in the so called traditional (conventional) type of firms nor in virtual ones. The tendencies towards automation and virtualization shall be considered under their strategic aspects, such as competitive advantage gained through the combined use of such technologies, knowledge management and organizational learning. Specific aspects related to strategies about generation, retention $e$ dissemination of knowledge, within the organizations and related collaborators and partners, as well as their dynamic and possible impacts about the firms' results, consist the main concern of the present work.
\end{abstract}

\section{PALAVRAS-CHAVE}

Gestão do conhecimento, capital intelectual, aprendizado organizacional, tecnologia da informação, valor.

\section{KEY WORDS}

Knowledge management, intellectual capital, organizational learning, information, technology, value. 


\section{INTRODUÇÃO}

As grandes mudanças nos cenários de atuação das empresas, tanto públicas quanto privadas, em especial nesta Era da Informação e Conhecimento, nos permitem imaginar que uma fonte de vantagem competitiva nas empresas é seu ativo intangível 'conhecimento', e a efetiva gestão e aplicação deste ativo na expectativa de sua conversão em resultados. $\mathrm{O}$ objeto central de reflexão no presente trabalho é o processo de gestão de conhecimento nas organizações. O levantamento realizado está estruturado em literatura especializada em práticas de gestão e inovação organizacional.

O tema Gestão do Conhecimento faz fronteira com as diversas áreas de conhecimento das organizações, sendo multidisciplinar por excelência, pois o grau de conhecimento das organizações considera o conjunto de competências das diversas áreas que as compõem, tais como Planejamento, Mercadologia, Operações, Finanças e Gestão do Capital Humano, dentre outras, as quais, no seu conjunto, quando devidamente aplicadas, deverão permitir que as organizações estejam em condições de obter vantagens competitivas.

A área de Sistemas de Informação tem tido a responsabilidade de viabilizar tecnicamente projetos orientados para as mais diversas demandas - tanto aquelas com o intuito de dar apoio à melhoria de desempenho das pessoas das empresas, em especial aos tomadores de decisões, "voltados para problemas menos bem estruturados' SPRAGUE e WATSON (1991), sendo estas as características de projetos voltados para os Sistemas de Suporte à Decisão e Sistemas de Apoio ao Executivo - quanto outras demandas cujos conteúdos sejam bases de conhecimento, no formato de documentos, procedimentos e outras formas de conteúdo, sobre áreas de conhecimento de interesse da organização. Estas bases podem ser semi-estruturadas, onde, além de dados numéricos, freqüentemente se encontram gravados dados e informações em formatos variados, tais como texto, vídeo, som e outros formatos de arquivos. Estas bases de conhecimento buscam tornar as experiências, trabalhos e projetos em conhecimento documentado e passível de ser compartilhado, o que perfaz uma das possíveis formas ou processos de geração de conhecimentos.

\section{GESTÃO DO CONHECIMENTO E RESULTADOS}

Ao mencionar 'dar apoio à melhoria de desempenho das pessoas das empresas', a expectativa é de que melhoria de desempenho possa ser traduzida para melhoria de resultados. A palavra 'resultados' significando 'a forma que participantes racionais em uma economia baseada no mercado avaliam o valor de um ativo - a geração de caixa que pode ser esperada no decorrer do tempo, ajustada para o nível de risco do respectivo negócio’ (RAPPAPORT, 1998, p. xiii).

De acordo com o parágrafo anterior, a geração de valor deve ser analisada por uma perspectiva quantitativa, a qual pode vir a ser representada como o valor agregado de mercado (Market Value Added-MVA). Este indicador de desempenho, cuja fundamentação teórica é apoiada no método de valor presente de orçamento de capital e na abordagem Valuation, de autoria dos Professores Miller e Modigliani (COPELAND et al., 1995, p. xiii), é um suporte para a tomada de decisões, decisões estas orientadas para a tentativa de maximização de valor aos acionistas. Em suma, considerando-se que o indicador tem vistas ao potencial do negócio em gerar fluxo de caixa em períodos futuros, este valor projetado deve ser trazido para valor presente e será equivalente ao valor do negócio. 


\section{GESTÃO DA INFORMAÇÃO - ORGANIZAÇÕES NO ESPAÇO CIBERNÉTICO: \\ ESTUDO COMPARATIVO ALTAVISTA E AMAZON BOOKS \\ William Sampaio Francini}

Pelo acima exposto, é inferência do autor que a decisão lógica de se investir em uma empresa A em detrimento de outra B se dará quando o investidor puder ter acesso aos fluxos de caixa projetados de ambas e comparar que uma unidade de dinheiro investida em A trará um retorno superior ao investimento equivalente em $\mathrm{B}$, ou mesmo que A resultará em um retorno por ação ou cota superior a B. O retorno superior em A pode ser representado como um indicativo de sucesso da empresa analisada.

Como indica RAPPAPORT (1998), o termo geração de valor para o acionista assume o sentido equivalente a valor econômico total do negócio menos seus débitos, sendo que, a fim de apurar-se o potencial de um negócio gerar valor para o acionista, ou o valor patrimonial do acionista, deve-se definir inicialmente o valor econômico total do negócio, que consiste nos seguintes componentes básicos:

a) O valor presente dos fluxos de caixa gerados das operações durante o período de previsões;

b) O 'valor residual', o qual representa o valor presente do negócio que se atribui ao período posterior ao período de previsões (de fluxos de caixa);

c) Para uma estimação mais precisa de valor corporativo, um terceiro componente deve ser incluído: o valor presente de ativos negociáveis e outros investimentos que possam ser convertidos em caixa e não sejam essenciais para operar o negócio.

\section{A IMPORTÂNCIA DA GESTÃO DO CONHECIMENTO}

A combinação de indicadores tradicionais com medições que tragam outras percepções e visões - tais como a tentativa do estabelecimento de uma relação causal entre a formalização do processo de gestão do conhecimento e a geração de valor ao acionista, ou mesmo os esforços voltados para a mensuração do valor do ativo intangível 'capital intelectual' - possivelmente poderá resultar em novos tipos de indicadores de desempenho, que venham a apoiar a gestão de negócios.

Com base em observações de relatórios anuais de empresas públicas e privadas, nacionais ou internacionais, publicados em revistas e jornais, que incluem seus balanços patrimoniais, acredito que, até o momento, as formas de mensuração de valor gerado por conseqüência de investimentos em gestão do conhecimento, ou mesmo as formas de dimensionamento do próprio capital intelectual, estejam relativamente pouco difundidas e mais diretamente ligadas à dimensão de percepção de valor agregado, sendo, porém, algo ainda bastante sujeito ao juízo de valor de cada indivíduo e da cultura de cada organização.

Diversos são os casos de organizações que, além de procurar as melhores escolas, fundações e outras instituições para a educação continuada, capacitação e treinamento, desenvolvem as 'universidades empresariais internas', onde buscam obter, gerar e compartilhar o seu próprio conhecimento organizacional, estando alinhados com suas estratégias e culturas, no intuito de aumentar a probabilidade de atingir e mesmo superar seus objetivos.

Uma argumentação que dá sustentação a ações como as acima mencionadas é feita por QUINN (1992), cuja colocação 'virtualmente todas as corporações públicas e privadas - incluindo-se a maioria das empresas bem sucedidas - estão se tornando predominantemente repositórios e coordenadores de intelecto, i.e., companhias 'baseadas no conhecimento' ou 'inteligentes'. Intelecto e serviços criam valor agregado. 
A capacidade de gerenciar o intelecto humano - e de transformar output intelectual em um serviço ou um grupo de serviços embutidos em um produto - está rapidamente se tornando a habilidade executiva crítica desta era', bem ilustra as principais preocupações das organizações, inclusive para os próximos anos (trad. pelo autor).

Outro ponto de vista nos é apresentado, com relação à percepção de 'valor agregado' e grau de sucesso de empresas, por NONAKA e TAKEUCHI (1995), que, conforme indicam os casos das empresas por eles estudadas no Japão, estas têm sido bem sucedidas 'por causa de suas habilidades e expertise em 'criação de conhecimento organizacional'. Estes autores definem 'criação de conhecimento organizacional' como a 'capacidade da companhia como um todo criar novo conhecimento, disseminálo através da organização, e embuti-lo em produtos, serviços e sistemas’.

Considerando-se a perspectiva proposta para os indicadores-chave de desempenho das organizações em The Balanced Scorecard, KAPLAN e NORTON (1996) sugerem que mudanças significativas em desempenho requerem mudanças de porte considerável, inclusive nos sistemas de mensuração e de gestão das organizações. Sistemas de acompanhamento de resultados financeiros realizados talvez não sejam suficientes para a administração de negócios atual, em ambientes cada vez mais competitivos, tecnológicos e capacitados.

\section{CAPITAL INTELECTUAL: INTANGIBILIDADE E VALOR}

A abordagem de EDVINSSON e MALONE (1998) apresenta uma visão ampliada sobre o valor de ativos, com enfoque principal sobre a gestão do Capital Intelectual (CI), como 'mais do que a simples gestão do conhecimento ou da propriedade intelectual. A gestão do CI é, na realidade, a alavancagem da combinação entre capital humano e capital estrutural', pontos estes que serão mais profundamente abordados na próxima parte deste documento.

A gestão do conhecimento nas organizações tem sido foco de investimentos crescentes, através de melhor capacitação e desenvolvimento do fator humano. BRANDÃO e GUIMARÃES, Revista de Administração de Empresas (vol. 41, Num. 1, p. 9, 2001, doravante citada como RAE) abordam 'a gestão de competências e a gestão de desempenho como instrumentos que fazem parte de um mesmo movimento, voltado a oferecer alternativas eficientes de gestão às organizações'. A interpretação deste autor quanto às características da gestão do fator humano, é de que as políticas empresariais atuais buscam desenvolver suas competências, a fim de aumentar as respectivas chances de atingir seus objetivos estratégicos, via melhoria da qualidade nos processos de solução de problemas, negociações e de tomada de decisões.

É de conhecimento público que muitos conceitos e técnicas foram desenvolvidos na última década com o intuito de permitir às organizações se tornarem mais competitivas e bem-sucedidas, tais como reengenharia e gestão de processos, gestão da qualidade, gestão de custos baseada em atividades e orientação para atendimento das necessidades do cliente, dentre outros. Uma parte destes esforços de implantação se traduz em sucesso e outra em fracasso para as empresas.

"Há uma possibilidade de que a causa dos fracassos tenha sido a falta de vínculo destes programas com a estratégia organizacional, ou ainda a resultados econômicos e financeiros. A navegação em ambientes futuros mais competitivos, tecnológicos e direcionados à capacitação não pode ser atingida meramente ao se monitorar e controlar medidas financeiras de desempenhos passados" (KAPLAN, 1996, p.6). 
A sugestão implícita é de que devem operar com vistas ao futuro, utilizarem novas métricas para a gestão da empresa, e inclusive acompanhar novos objetos de custeio e valor.

Em Capital Intelectual, Descobrindo o Valor Real de Sua Empresa pela Identificação de Seus Valores Internos é apresentado um sistema de mensuração de capital intelectual (CI) que busca trazer novas dimensões de gestão, como a gestão do Capital Intelectual, e demonstrar seu impacto na geração de valor econômico agregado (EDVINSSON e MALONE, 1997).

Por outro lado, conforme citado em A Nova Riqueza das Organizações: Gerenciando e Avaliando Patrimônios de Conhecimento: "Parece haver consenso em relação ao velho mundo; vamos chamá-lo de paradigma industrial. Todos concordam que estamos abandonando a maneira industrial de ver o mundo, mas ninguém pode afirmar com certeza o que está por vir...Entretanto, parece mais razoavelmente óbvio que informação e conhecimento, no sentido mais amplo, estão adquirindo mais importância. Assim por mais que descrevamos a nova sociedade que estamos criando, faz mais sentido vê-la em termos de conhecimento" (SVEIBY, 1997).

Já vivemos em um mundo no qual os serviços constituem mais de dois terços do produto nacional bruto (PIB) dos empregos, por isso devemos mudar nossa perspectiva - ou paradigma - para algo que possamos chamar de economia do conhecimento ou de serviço (QUINN, 1992). Percebe-se ainda nos dias atuais que empresas devem estar operando dentro de paradigmas ultrapassados, as quais deixam de ser tão competitivas quanto poderiam, ao desconsiderar oportunidades estratégicas relacionadas à inovação, adoção de novas tecnologias e processos, por não terem tido contato com idéias e formas de gestão mais atualizadas, ou por estarem acomodadas em seu status, até o momento, confortável. A título de exemplificação, uma perspectiva de paradigma ultrapassado pode ser a excessiva orientação a produtos, enquanto é sabido que as empresas de maior sucesso na atualidade, de qualquer setor da economia, são aquelas que sabem ouvir e atender seus clientes, tendo uma orientação ao mercado. "Uma mudança de paradigma se instala quando uma proporção suficiente de pessoas muda sua maneira de ver o mundo e começa a enxergar os fenômenos com uma nova perspectiva compartilhada. É muito difícil "ver" um novo paradigma porque a maioria das pessoas continua presa pela linguagem do antigo paradigma enquanto luta para definir o novo" (KUHN, 1962, citado por SVEIBY, 1997, p. 31).

O rótulo escolhido por Sveiby para o novo paradigma do conhecimento é vendo o mundo pelo ponto de vista do conhecimento.

O quadro a seguir procura descrever como o referido autor interpreta o que está acontecendo no mundo dos negócios, sendo que a coluna da direita sintetiza os princípios que regem a organização projetada como um arquétipo do futuro: a organização do conhecimento. 
Tabela 1 - A Era da Organização do Conhecimento

\begin{tabular}{|c|c|c|}
\hline Item & $\begin{array}{l}\text { Visto pelo paradigma } \\
\text { industrial, ou de uma } \\
\text { perspectiva industrial }\end{array}$ & $\begin{array}{l}\text { Visto pelo paradigma do } \\
\text { conhecimento, ou de uma } \\
\text { perspectiva do conheciment }\end{array}$ \\
\hline Pessoas & Geradores de custo ou recursos & Geradores de receita \\
\hline $\begin{array}{l}\text { Base de poder dos } \\
\text { gerentes }\end{array}$ & $\begin{array}{l}\text { Nível relativo na hierarquia } \\
\text { organizacional }\end{array}$ & Nível relativo de conhecimento \\
\hline Luta de poder & $\begin{array}{l}\text { Trabalhadores físicos versus } \\
\text { capitalistas }\end{array}$ & $\begin{array}{l}\text { Trabalhadores do conhecimento } \\
\text { versus gerentes }\end{array}$ \\
\hline $\begin{array}{l}\text { Principal tarefa da } \\
\text { gerência }\end{array}$ & Supervisão de subordinados & Apoio aos colegas \\
\hline Informação & Instrumento de controle & $\begin{array}{l}\text { Ferramenta para o recurso da } \\
\text { comunicação }\end{array}$ \\
\hline Produção & $\begin{array}{l}\text { Trabalhadores físicos } \\
\text { processando recursos físicos para } \\
\text { criar produtos tangíveis }\end{array}$ & $\begin{array}{l}\text { Trabalhadores do conhecimento } \\
\text { convertendo conhecimento em } \\
\text { estruturas intangíveis }\end{array}$ \\
\hline $\begin{array}{l}\text { Fluxo de } \\
\text { informações }\end{array}$ & Via hierarquia organizacional & Via redes colegiadas \\
\hline $\begin{array}{l}\text { Forma básica de } \\
\text { receita }\end{array}$ & Tangível (dinheiro) & $\begin{array}{l}\text { Intangível (aprendizado, novas } \\
\text { idéias, novos clientes, } P \& D \text { ) }\end{array}$ \\
\hline $\begin{array}{l}\text { Estrangulamentos } \\
\text { na produção }\end{array}$ & $\begin{array}{l}\text { Capital financeiro e habilidades } \\
\text { humanas }\end{array}$ & Tempo e conhecimento \\
\hline $\begin{array}{l}\text { Manifestação da } \\
\text { produção }\end{array}$ & Produtos tangíveis (hardware) & $\begin{array}{l}\text { Estruturas intangíveis (conceitos } \\
\text { e software) }\end{array}$ \\
\hline Fluxo de produção & Regido pela máquina, sequencial & Regido pelas idéias, caótico \\
\hline Efeito do porte & $\begin{array}{l}\text { Economia de escala no processo } \\
\text { de produção }\end{array}$ & Economia de escopo das redes \\
\hline $\begin{array}{l}\text { Relacionamento } \\
\text { com o cliente }\end{array}$ & Unilateral pelos mercados & Interativo pelas redes pessoais \\
\hline Conhecimento & $\begin{array}{l}\text { Uma ferramenta ou um recurso } \\
\text { entre outros }\end{array}$ & O foco empresarial \\
\hline $\begin{array}{l}\text { Finalidade do } \\
\text { aprendizado }\end{array}$ & Aplicação de novas ferramentas & Criação de novos ativos \\
\hline $\begin{array}{l}\text { Valores do } \\
\text { mercado acionário }\end{array}$ & Regidos pelos ativos tangíveis & Regidos pelos ativos intangíveis \\
\hline Economia & De redução de lucros & De aumento e redução de lucros \\
\hline
\end{tabular}

Fonte: SVEIBY, (1997).

A fim de ilustrar o papel do Capital Intelectual, EDVINSSON e MALONE (1997) propõem uma metáfora, através da qual comparam as organizações a organismos vivos, mais especificamente com uma árvore, "então o que é descrito em organogramas, relatórios anuais, demonstrativos financeiros 
trimestrais, brochuras explicativas e outros documentos constitui o tronco, os galhos e as folhas. O investidor inteligente examina essa árvore em busca de frutos maduros para colher. Presumir, porém, que essa é a árvore inteira, por representar tudo que seja imediatamente visível, é certamente um erro. Metade da massa, ou o maior conteúdo dessa árvore, encontra-se abaixo da superfície, no sistema de raízes. [...] Compreender o que acontece nas raízes é uma maneira muito mais eficaz para conhecer quão saudável a árvore em questão será nos anos vindouros”.

Através desta metáfora, é destacado ainda que o estudo das raízes do valor de uma empresa, a mensuração dos fatores dinâmicos ocultos que embasam a empresa invisível formada por edifícios e produtos, é o que torna o Capital Intelectual tão valioso.

De acordo com pesquisas realizadas pela companhia de seguros Skandia, sob coordenação de Sveiby, citados por EDVINSSON e MALONE (1997), esses fatores assumem tipicamente duas formas:

a) Capital Humano. O conhecimento, a experiência, o poder de inovação e a habilidade dos empregados de uma companhia para realizar as tarefas do dia-a-dia. Inclui também os valores, a cultura e filosofia da empresa. Neste caso, porém, o capital humano não constitui propriedade da empresa.

b) Capital Estrutural. Os equipamentos de informática, os software, os bancos de dados, as patentes, as marcas registradas e todo o resto da capacidade organizacional que apóia a produtividade daqueles empregados - em poucas palavras, tudo o que permanece no escritório quando os empregados vão para casa. $O$ capital estrutural também inclui o capital de cliente, o relacionamento desenvolvido com os principais clientes. Ao contrário do capital humano, o capital estrutural pode ser possuído e, portanto, negociado.

Em suma, a proposta é:

Capital Humano + Capital Estrutural $=$ Capital Intelectual

“É fácil ver que o Capital Intelectual não se enquadra nos modelos contábeis tradicionais. O Capital Intelectual, em especial, valoriza atividades como a lealdade dos clientes, e o desenvolvimento da competência dos empregados. O reconhecimento desta nova realidade empresarial está forçando a emergência de um novo equilíbrio, em que o passado é computado levando-se em conta o futuro, e os aspectos financeiros são influenciados pelos não-financeiros - o Capital Intelectual." EDVINSSON e MALONE (1997, p. 10).

O Capital Humano é conseqüência direta do somatório das especialidades e habilidades de seus empregados, e, portanto, não pertence à empresa.

O Capital Estrutural pertence à empresa, e constitui o ambiente real construído pela companhia. É composto por todos os processos internos e externos que existem dentro da companhia. 
O estabelecimento de um "Novo Balanço", na perspectiva do Conhecimento, pode ser apresentado da seguinte forma esquemática (EDVINSSON e MALONE, 1997):

Capital Intelectual $=$

Capital Originário do Conhecimento $=$

Ativos Não Financeiros $=$

Ativos Ocultos $=$

Ativos Invisíveis $=$

Meios para se Alcançar as Metas =

$$
\mathrm{CI}=\mathrm{VM}-\mathrm{VC}(\text { James Tobin) }
$$

$=$

\section{Capital Intelectual $=$ Valor de Mercado menos o Valor Contábil}

Nesta proposição, contudo, é evitado o uso de valores absolutos, "pois não tem utilidade alguma o estabelecimento de quanto soma em dólares o Capital Intelectual de determinada empresa. A relação Valor de Mercado para Valor Contábil (M/C) será usada como um padrão eficaz para medir ativos intangíveis" (JOIA, RAE, vol. 41, p. 54, 2001).

No referido artigo é proposto o uso de uma taxonomia para o capital corporativo, assumindo-se que:

$$
\text { Valor de Mercado = Valor Contábil + Capital Intelectual. }
$$

A equação acima mostra que o valor das ações das empresas tem uma porção tangível (valor contábil), além de um componente intangível.

Assume-se que, ainda de acordo com o referido artigo, "quanto mais conhecimento a empresa possuir, maior será o valor de M/C", conforme demonstrado na tabela a seguir (STEWART, 1997, citado por JOIA, 2001):

TABELA 2 - Valores (M/C)

\begin{tabular}{|l|c|c|c|}
\hline \multicolumn{1}{|c|}{ Empresa } & Valor de Mercado & Valor Contábil & M/C \\
\hline IBM & US\$ 70,7 bilhões & US\$ 16,6 bilhões & 4,25 \\
\hline Microsoft & US\$ 85,5 bilhões & US\$ 930 milhões & 91,93 \\
\hline
\end{tabular}


Fonte: RAE, vol. 41, p. 55, 2001. Valores de novembro de 1996

O mercado percebe na Microsoft um elemento de valor intangível muito maior do que na IBM. No caso, utiliza-se o custo de substituição para contornar políticas diferenciadas de depreciação, onde se define $q$ como (Valor de Mercado)/(Custo de Substituição dos Ativos). Se $q$ for maior que 1, o ativo vale mais do que o custo de substituí-lo, portanto é mais provável que a empresa procure adquirir mais ativo deste tipo. Calcula-se então, o valor contábil pela seguinte fórmula:

Valor Contábil $=$ Capital Monetário + Capital Físico

Por outro lado “o Capital Estrutural pertence à empresa e pode ser negociado (pelo menos em teoria), sendo o ambiente real construído pela companhia para administrar e gerar seu conhecimento de forma adequada. É composto por todos os processos internos e externos que existem dentro da empresa e entre ela e seus outros parceiros (capital de processos); pelo capital de relacionamento, ligado aos fornecedores, clientes, prestadores de serviços e outros parceiros individuais envolvidos; e pelo capital de inovação, uma conseqüência direta da cultura da empresa e sua capacidade de criar conhecimento novo com base no conhecimento existente" (JOIA, RAE, vol. 41, p. 54, 2001). Desta forma, temos:

\section{Capital Estrutural $=$ Capital de Processos + Capital de Relacionamento + Capital de Inovação}

Por fim, a fórmula do Capital Intelectual completa:

Capital Intelectual $=$ Capital Humano + Capital de Processos + Capital de Relacionamento + Capital de Inovação

\section{Figura 1 - A taxonomia do Capital Intelectual}

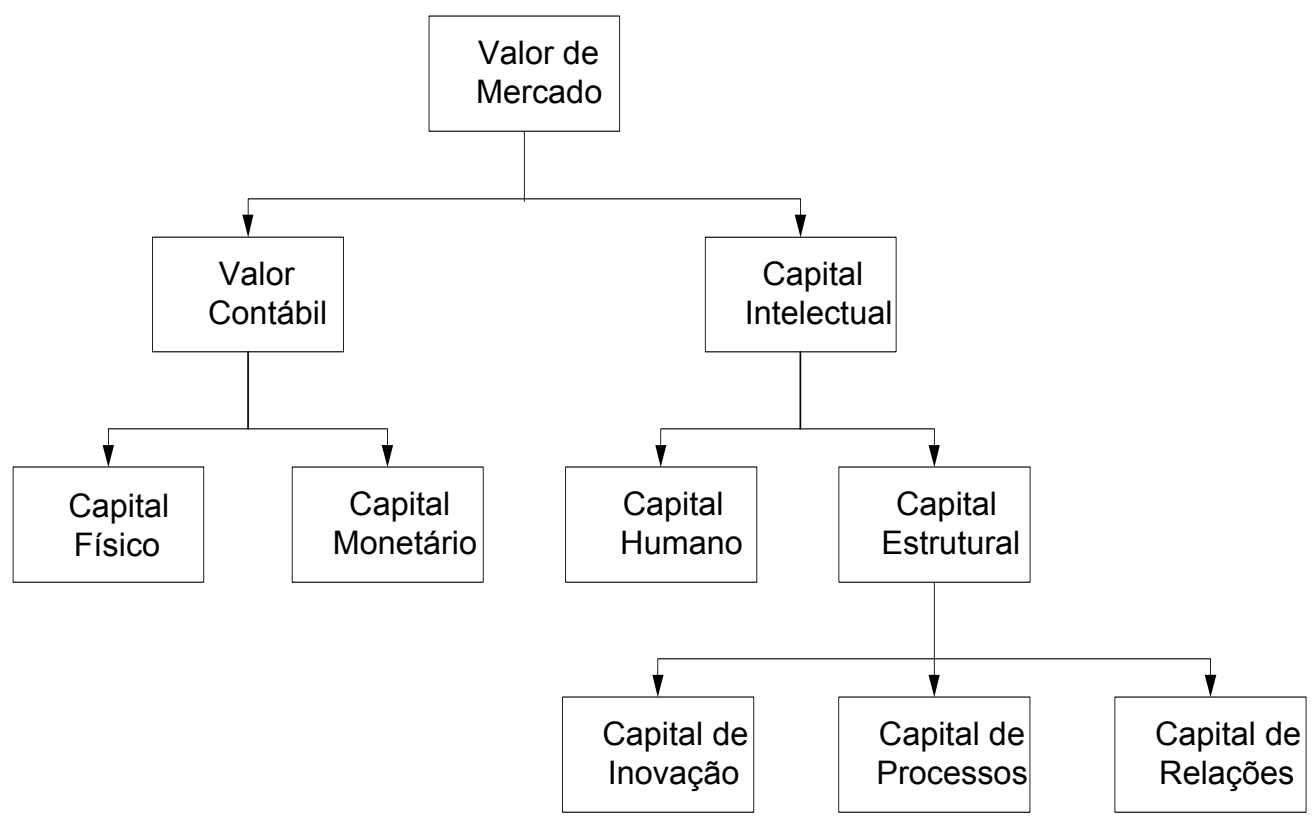


Fonte: JOIA (2001), em RAE, adaptado de EDVINSSON e MALONE (1997).

O Capital Humano, de Inovação, de Processos e de Relações - os ativos intangíveis - apresentam todos a mesma importância para a empresa.

\section{TIPOS DE CONHECIMENTO}

Entendo que seja importante destacar que o tipo de conhecimento aqui referenciado é o conhecimento científico, o qual trata do real (factual). TRUJILLO (1974, p. 11), citado por LAKATOS e MARCONI (1991), apresenta as características de quatro tipos de conhecimento:

\begin{tabular}{|c|c|c|c|}
\hline $\begin{array}{c}\text { Conhecimento } \\
\text { Popular }\end{array}$ & $\begin{array}{c}\text { Conhecimento } \\
\text { Científico }\end{array}$ & $\begin{array}{c}\text { Conhecimento } \\
\text { Filosófico }\end{array}$ & $\begin{array}{c}\text { Conhecimento } \\
\text { Religioso }\end{array}$ \\
\hline Valorativo & Real (factual) & Valorativo & Valorativo \\
\hline Reflexivo & Contingente & Racional & Inspiracional \\
\hline Assistemático & Sistemático & Sistemático & Sistemático \\
\hline Verificável & Verificável & Não verificável & Não verificável \\
\hline Falível & Falível & Infalível & Infalível \\
\hline Inexato & $\begin{array}{c}\text { Aproximadamente } \\
\text { exato }\end{array}$ & Exato & Exato \\
\hline
\end{tabular}

Para detalhamento mais amplo dos conceitos acima, ver LAKATOS e MARCONI, Metodologia Científica, 1991.

Além das características do conhecimento acima resumidas, destaco as seguintes, com base nas mesmas autoras:

\section{O Conhecimento Científico é Racional}

É constituído por conceitos, juízos e raciocínios e não por sensações, imagens e modelos de conduta. Tanto o ponto de partida quanto o de chegada são idéias (hipóteses).

Permite que as idéias que o compõem possam combinar-se segundo um conjunto de regras lógicas, com a finalidade de produzir novas idéias (inferência dedutiva).

Contém idéias que se organizam em sistemas, ou seja, conjuntos ordenados de proposições (teorias) e não idéias simplesmente aglomeradas ao acaso, ou mesmo cronologicamente.

Outra dimensão com relação a tipos de conhecimento nos é apresentada por POLANYI, (1966), para quem há uma distinção entre dois tipos de conhecimento: o conhecimento explícito e o conhecimento tácito. $\mathrm{O}$ conhecimento explícito é transmitido facilmente em idioma formal, de fácil expressão, e prontamente transferível em formato digital. O conhecimento tácito é difícil de comunicar usando-se o 
idioma formal, mas pode ser deduzido ou inferido por ações. Tipicamente irá requerer uma mídia mais rica - idealmente interação de face-a-face.

Usando esta distinção e a suposição que conhecimento pode ser convertido em novo conhecimento por uma interação formal entre conhecimento tácito e explícito, NONAKA e TAKEUCHI (1995) propõem quatro modos de criação de conhecimento: socialização, combinação, exteriorização e interiorização, como mostrado a seguir.

\section{TABELA 3 - MODELOS DE CRIAÇÃO DE CONHECIMENTO}

\begin{tabular}{|c|c|}
\hline MODELO & INTERAÇÃo ENTRE DOIS TIPOS DE CONHECIMENTO \\
\hline$\underline{\text { SOCIALIZAÇÃO }}$ & Comunicação de $\frac{\text { Conhecimento Tácito para Criação de Novo }}{\text { Conhecimento Tácito }}$ \\
\hline COMBINAÇÃO & $\begin{array}{c}\text { Comunicação de Conhecimento Explícito para Criação de } \\
\text { Novo Conhecimento Explícito }\end{array}$ \\
\hline$\underline{\text { EXTERIORIZAÇÃO }}$ & $\begin{array}{c}\text { Comunicação de Conhecimento Tácito para Criação de } \\
\text { Novo Conhecimento Explícito }\end{array}$ \\
\hline$\underline{\text { INTERIORIZAÇÃO }}$ & $\begin{array}{c}\text { Comunicação de Conhecimento Explícito para Criação de } \\
\text { Novo Conhecimento Tácito }\end{array}$ \\
\hline
\end{tabular}

Fonte: RIGGINS e RHEE, (1998).

Socialização é a conversão de conhecimento tácito em novo conhecimento tácito. Isto pode ser realizado interagindo com outros em uma base social, informal ou observando as ações deles/delas em uma relação do tipo "orientação" (mentoring). A aprendizagem que ocorre no trabalho é freqüentemente criação de conhecimento por socialização (RIGGINS e RHEE, 1998).

Em segundo, a combinação é um processo de sistematização de conceitos explícitos em um sistema de conhecimento, ou seja, é a combinação de diferentes partes de conhecimento explícito por meio da análise, da categorização e da reconfiguração de informações (SVEIBY, 1997).

Nos parágrafos a seguir, estão descritos exemplos tanto de formas de aprendizado interno quanto aprendizado interorganizacional, baseado em redes. Na definição de RIGGINS e RHEE:

'Combinação é o processo pelo qual conhecimento explícito novo pode ser criado ao se manipular ou combinar conhecimento explícito existente, ao colocá-lo em formas novas e mais significativas. Sistemas de informações gerenciais tradicionais resultam freqüentemente em criação de conhecimento por combinação. Isto acontece quando dados de transação detalhados são manipulados e reconfigurados em relatórios sumarizados e consolidados, os quais resultam em novos insights para os gestores'.

A interação entre conhecimento tácito e explícito resulta em interiorização e exteriorização. A exteriorização é o processo de conversão de conhecimento tácito em conhecimento explícito, 


\section{GESTÃO DA INFORMAÇÃO - ORGANIZAÇÕES NO ESPAÇO CIBERNÉTICO: \\ ESTUDO COMPARATIVO ALTAVISTA E AMAZON BOOKS \\ William Sampaio Francini}

freqüentemente pelo uso de metáforas e analogias. Em outras palavras, 'expressam em uma forma reduzida e um tanto distorcida o conhecimento tácito de um indivíduo’ (SVEIBY, 1997).

Finalmente, interiorização é a conversão de conhecimento explícito existente em conhecimento tácito novo. Está relacionado ao aprendizado pela prática, isto é, relacionado de perto ao uso típico do termo "que aprende".

'Por ser o conhecimento explícito menos abstrato e facilmente articulado em linguagem formal, é convertido facilmente em formato eletrônico, transmitido em linhas de telecomunicações de baixa largura de banda e interpretado pelo receptor em conhecimento explícito adicional. Por causa disto, a maioria das trocas de dados via sistemas interorganizacionais resulta somente na criação de conhecimento por combinação. Realmente, o conceito de combinação está baseado no paradigma de processamento de informação’ (RIGGINS e RHEE, 1998, trad. pelo autor).

Enquanto cada tipo de criação de conhecimento é importante, o modelo dinâmico de criação de conhecimento de Nonaka está baseado em um processo por meio do qual todos os quatro modos de criação de conhecimento são gerenciados, em um ciclo contínuo ou "processo em espiral".

\section{DIAGRAMA 1 - Processo de Criação de Conhecimento e de Vantagens Competitivas}

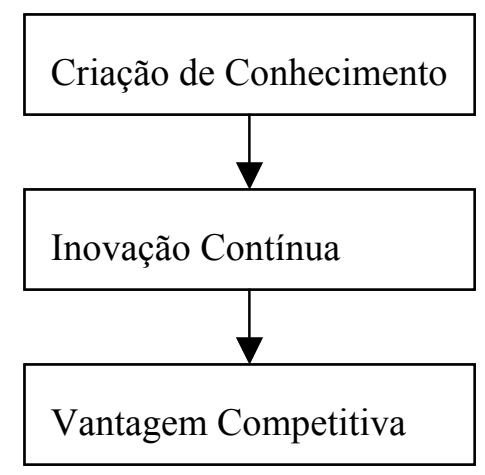

Fonte: NONAKA e TAKEUCHI - The Knowledge Creating Company

\section{APRENDIZADO ORGANIZACIONAL}

Por outro lado, de acordo com CROSSAN, LANE e WHITE (2001), a discussão em torno de gestão de conhecimento e aprendizado organizacional cresceu muito nos últimos anos, mas ainda há uma carência de uma teoria geral de aprendizado organizacional. E isto se deve, ao menos em parte, devido ao fato de que os pesquisadores aplicaram o conceito de aprendizado organizacional para diferentes domínios. Ainda de acordo com estes autores, 'o foco do trabalho está na renovação estratégica - este é portanto, o fenômeno de interesse básico'

Conforme sintetizado na tabela a seguir, podemos constatar uma visão panorâmica que abrange parcialmente as anteriormente apresentadas, assim como as caracteriza. 
TABELA 4 -Estruturas para o Aprendizado Organizacional

\begin{tabular}{|l|l|l|l|l|l|}
\hline Fonte & $\begin{array}{l}\text { Tensão por } \\
\text { Renovação } \\
\text { Estratégica }\end{array}$ & $\begin{array}{l}\text { Estrutura de } \\
\text { Múltiplos Níveis }\end{array}$ & $\begin{array}{l}\text { Um nível } \\
\text { afeta outro }\end{array}$ & $\begin{array}{l}\text { Níveis de } \\
\text { Comunicação dos } \\
\text { Processos }\end{array}$ & $\begin{array}{l}\text { Comunicação } \\
\text { entre } \\
\text { Cognição/Ação }\end{array}$ \\
\hline
\end{tabular}

\begin{tabular}{|c|c|c|c|c|c|}
\hline $\begin{array}{l}\text { March \& } \\
\text { Olsen } \\
(1975)\end{array}$ & $\begin{array}{l}\text { Não } \\
\text { considerada }\end{array}$ & $\begin{array}{l}\text { Não há níveis de } \\
\text { grupo }\end{array}$ & $\begin{array}{l}\text { Não } \\
\text { considerada }\end{array}$ & Não considerada & Sim \\
\hline $\begin{array}{l}\text { Daft \& } \\
\text { Weick } \\
(1984)\end{array}$ & $\begin{array}{l}\text { Não } \\
\text { considerada }\end{array}$ & Não considerada & $\begin{array}{l}\text { Não } \\
\text { considerada }\end{array}$ & $\begin{array}{l}\text { Processo descrito } \\
\text { mas não uma } \\
\text { perspectiva de } \\
\text { níveis }\end{array}$ & $\begin{array}{l}\text { Aprendizado é } \\
\text { uma mudança no } \\
\text { comportamento }\end{array}$ \\
\hline $\begin{array}{l}\text { Senge } \\
(1990)\end{array}$ & $\begin{array}{l}\text { Não } \\
\text { considerada }\end{array}$ & $\begin{array}{l}\text { Não há níveis } \\
\text { organizacionais }\end{array}$ & $\begin{array}{l}\text { Não } \\
\text { considerada }\end{array}$ & $\begin{array}{l}\text { Processos enfocam } \\
\text { o indivíduo e o } \\
\text { grupo - não é um } \\
\text { modelo de níveis } \\
\text { que se relacionam }\end{array}$ & Sim \\
\hline $\begin{array}{l}\text { Huber } \\
(1991)\end{array}$ & $\begin{array}{l}\text { Não } \\
\text { considerada }\end{array}$ & Sim & $\begin{array}{l}\text { Não } \\
\text { considerada }\end{array}$ & $\begin{array}{l}\text { Processos dentro } \\
\text { do mesmo nível } \\
\text { mas nenhum } \\
\text { modelo ou } \\
\text { processo para } \\
\text { comunicar níveis }\end{array}$ & $\begin{array}{l}\text { Cognição afeta } \\
\text { comportamentos }\end{array}$ \\
\hline $\begin{array}{l}\text { March } \\
(1991)\end{array}$ & Sim & $\begin{array}{l}\text { Não há níveis de } \\
\text { grupo }\end{array}$ & $\begin{array}{l}\text { Não } \\
\text { considerada }\end{array}$ & Não considerada & Sim \\
\hline $\begin{array}{l}\text { Watkins } \\
\& \\
\text { Marsick } \\
(1993)\end{array}$ & $\begin{array}{l}\text { Não } \\
\text { considerada }\end{array}$ & Sim & $\begin{array}{l}\text { Não } \\
\text { considerada }\end{array}$ & $\begin{array}{l}\text { Seis imperativos } \\
\text { da empresa que } \\
\text { aprende }\end{array}$ & $\begin{array}{l}\text { Consistente com a } \\
\text { perspectiva de } \\
\text { Senge }\end{array}$ \\
\hline $\begin{array}{l}\text { Nonaka \& } \\
\text { Takeuchi } \\
(1995)\end{array}$ & $\begin{array}{l}\text { Não } \\
\text { considerada }\end{array}$ & $\begin{array}{l}\text { Reconhecido, } \\
\text { mas não é uma } \\
\text { parte substancial } \\
\text { do modelo }\end{array}$ & $\begin{array}{l}\text { Alguma } \\
\text { discussão } \\
\text { da } \\
\text { comunicaçã } \\
\text { o entre } \\
\text { indivíduo e } \\
\text { grupo }\end{array}$ & $\begin{array}{l}\text { Enfoca processos } \\
\text { que ligam } \\
\text { indivíduos e grupo } \\
\text { - fraco na } \\
\text { comunicação entre } \\
\text { grupo e } \\
\text { organização }\end{array}$ & $\begin{array}{l}\text { Enfoque no } \\
\text { conhecimento }\end{array}$ \\
\hline
\end{tabular}

'Aprendizado organizacional estabelece uma conexão entre cognição e ação. Isto o diferencia dos campos correlacionados gestão do conhecimento e capital intelectual. Apesar de argumentos ao contrário (NONAKA e TAKEUCHI, 1995, citados por CROSSAN, LANE \& WHITE, 2001), os campos de gestão do conhecimento e capital intelectual permanecem fortemente focados em cognição. 
Contudo, estes campos compartilham um campo comum com aprendizado organizacional ao reconhecer a importância do conhecimento para o sucesso da organização.' (CROSSAN, LANE \& WHITE, 2001). Estes autores propõem um framework para o aprendizado organizacional que contém quatro processos correlacionados - intuição, interpretação, integração e institucionalização - que ocorrem em três níveis: individual, grupo e organização. Conforme ilustram estes autores, 'ademais, mesmo que indivíduos estejam interpretando coisas de relevância, seu aprendizado precisa ser integrado e institucionalizado para realizar seu valor futuro. Esta teoria sugere não se tratar simplesmente de uma questão de transferência de dados, informação ou conhecimento - é uma questão de aprendizado organizacional.'. E concluem, no entendimento deste autor, que o 'aprendizado organizacional pode ser concebido como o principal meio de se atingir a renovação estratégica de uma corporação.' (trad. pelo autor).

\section{IMPLICAÇÕES FINAIS}

A presente discussão aborda três assuntos, creio, interconectados: gestão do conhecimento, capital intelectual e aprendizado organizacional. Estes três pontos vêm chamando a atenção de pesquisadores e especialistas das mais diversas áreas, sendo que os profissionais - acadêmicos e executivos - vêm sendo chamados à responsabilidade de operacionalizar projetos focados nos assuntos acima. Neste ponto, a discussão apresentada está orientada para um conjunto de afirmações, baseado em pesquisa bibliográfica, não tendo o autor deste realizado pesquisa empírica sobre os assuntos abordados. Por conseguinte, o objetivo do artigo é apresentar uma visão panorâmica a respeito das questões colocadas, e, com isto, alguma contribuição ao leitor.

\section{Artigo recebido em 06.06.2001. Aprovado em 10.06.2002}

\section{REFERÊNCIAS BIBLIOGRÁFICAS}

BRANDÃO, H., GUIMARÃES, T . Revista de Administração de Empresas - vol. 41, Num. 1, p. 9, 2001.

CROSSAN, M., LANE H. e WHITE, R. - An Organizational Learning Framework: From Intuition To Institution, Academy of Management Review, Vol. 24, Num. 3, 522 - 537, 1999.

EDVINSSON, L. e MALONE, M. - Intellectual Capital: Realizing Your Company's True Value by Finding its Hidden Brainpower, Harper Collins Publishers Inc., 1998.

JOIA, Luiz Antonio - "Medindo o Capital Intelectual” - RAE, vol. 41, p. 54, 2001.

KUHN, T. - A Estrutura das Revoluções Científicas, Ed. Perspectiva, 1962.

KAPLAN, R. e NORTON, D. - The Balanced Scorecard, Harvard Business School Press, 1996.

LAKATOS, E. e MARCONI, M. - Metodologia Científica, Ed. Atlas, 1991.

NONAKA, I. e TAKEUCHI, H. - The Knowledge-Creating Company: How Japanese Companies Create the Dynamics of Innovation, Oxford University Press, N.Y., 1995.

POLANYI, M., The Tacit Dimension, London, Routledge \& Kegan Paul, Ltd., 1966. 
QUINN, J. - The Intelligent Company, - The Free Press, N.Y., 1992.

RAPPAPORT, A. - Creating Shareholder Value, The Free Press, N.Y., 1998.

SENGE, P., The Fifth Discipline - The Art and Practice of the Learning Organization, Currency Doubleday, N.Y., 1990.

SPRAGUE, R. e WATSON, H., Sistema de Apoio à Decisão - Colocando a Teoria em Prática, Editora Campus, Rio de Janeiro, 1991.

SVEIBY, K. - A Nova Riqueza das Organizações: Gerenciando e Avaliando Patrimônios de Conhecimento, Ed. Campus, 1998, trad. do original, 1997.

RIGGINS, J. e RHEE, H. - Developing the Learning Network Using Extranets, DuPree College of Management, 